\title{
Numerical simulation of hydraulic processes in anaerobic bioreactors
}

\author{
V. Klimova, I. Shcelomentsev, I. Burdin \& S. Shcheklein \\ Department of Nuclear Power Plants and Renewables, \\ Ural Federal University, Russia
}

\begin{abstract}
The aim of the work was to determine the rate and uniformity of temperature distribution in the amount of biogas plant constructed by UrFU, "Avanguard" PLC and "Gildia-M" Ltd on the stage of warming and achieving the rated work conditions corresponding to the mesophilic fermentation process. A computer model of the biogas reactor, considering the main unit features, was created. The installation heating was carried out by uniform thermal energy supply through the outer surface of the vessel full of substrate. Numerical solution was achieved by the finite volume method which has the following features. The calculation results in the form of temperature fields and the substrate particle trajectories for several time moments are given in this paper. The results analysis shows the possibility to use the model for the thermohydraulic computation of various operation modes of the bioreactor.
\end{abstract}

Keywords: mesophilic fermentation process, biogas, simulation, transient mode.

\section{Introduction}

The human race has been widely using the fuels of vegetable origin from the very beginning of civilization. Nowadays, a large amount of production and waste of agriculture, including animal husbandry, and food industry is added to natural biomass (grass, wood etc.). Current technologies of acid and fermentative hydrolysis, gas production, pyrolysis allow to produce motor fuels, biogas, highenergy solid fuels from biomass [1-3], as opposed to conventional burning which can provide just heat energy.

Natural biomass is the wealth of our planet, but plenty of organic waste of agriculture and food industry can be not only the potential resource of bioenergy 
but an environmental hazard. Conventional ways of organic waste processing are complicated enough in terms of technology and demand high power inputs. It gives one more incentive to introduce the technologies of fuel production from biomass.

The production of biogas consisting mainly of methane and carbon dioxide is one of the most developed methods to convert biomass into fuel. The technology is based on the process of anaerobic bacterial fermentation. The process of organic substances fermentation runs in a bioreactor (the so-called methatank) without air access (anaerobic conditions) by relatively high temperature. Biogas escapes in the course of fermentation reaction. In the residue it is formed the organic fertilizer which does not contain pathogenic germ or weed seeds and can be used in agriculture [2].

The production of methane in biogas reactors can not only solve the problem of waste utilization but supply agricultural enterprises with self-made cheap energy resource. Biogas can be used as a fuel for household gas devices, gas water heaters, air heaters. It also can be used for electric power generation in gasfired plants [1].

\section{The description of the biogas facility}

The Department of Atomic Power Plants and Renewables, Ural Federal University, together with "Avanguard" PLC and "Gildia-M" Ltd have designed a biogas facility to produce methane from animal waste. The facility is intended to operate in the conditions of moderate and frigid climatic zones of Russia characterized by low temperatures. The facility flow diagram is shown in fig. 1 .

The organic waste is accumulated in the dung collector (1). The supply pump (2) sends it in the grinder system (3), than ground dung comes into the suction tank of the anaerobic reactor. After the stage of preparation it is transported into the main tank of the anaerobic reactor (6) by the substrate pump (4). The anaerobic reactor has a mixing system with electric drive (5) which improves the uniformity of the gasification process. Biogas is removed from the reactor with gas compressor (7) to the dehumidification system (8), and the used substrate comes into the separation system (10) with the help of the pump (9). Dry biogas is accumulated in the gasholder (11), from where it can be sent to the consumer (12). Water from the dehumidification system (8) comes to the separation system (10). Separated water is sent back in the bioreactor (6) with the regeneration pump (15). The off-balance water is removed from the cycle through the purification and sterilization system (13), and some of waste heat is reused for the tank heating (14).

The anaerobic methane generation from biomass is provided by the enzymatic ferment microorganisms which are present in the animal dung. The same process of organic decomposition we can meet in natural conditions of swamp, soil or animal bowels. Without oxygen or other energetically preferable electron acceptor access the bacteria have to use organic carbon and produce the most restored hydrocarbon compound - methane. Bacteria use the same carbon as an electron donor oxidizing it up to carbon-dioxide gas. 


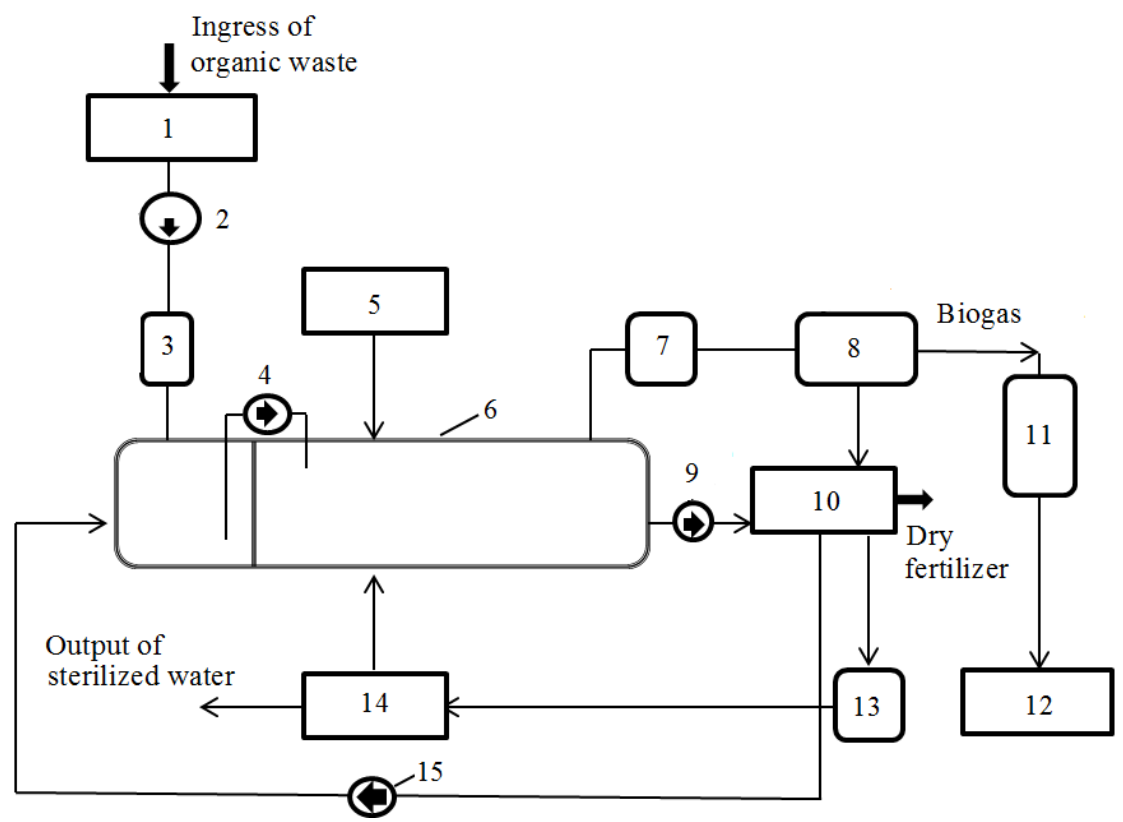

Figure 1: Biogas facility flow diagram.

During the sequential process of organic decomposition various groups of bacteria destroy the carbon-carbonic bonds in the organic molecules. The process of anaerobic decomposition of nearly each organic substance can be divided into four stages [1]:

1) Hydrolysis of complex biopolymer molecules (proteins, lipids, polysaccharides etc.) into simpler monomers and oligomers such as amino acids, carbohydrates, fatty acids, etc.

2) Fermentation of the produced monomers to simpler acids and alcohols. Hydrogen and carbon acid are also produced at this stage.

3) Acetogenic stage of methane precursors (acetate, hydrogen, carbon acid) production.

4) Methanogenic stage leading to the complex organic substance decomposition end product - methane.

It should be mentioned that the stages of hydrolysis and fermentation are not legibly separated because the hydrolyzing microorganisms use the hydrolysis products for their growth.

Several hundreds of microorganism species participate in the decomposition process. Various groups of microorganisms are linked into complex food chains, for example methanogenic bacteria can't grow without the trophic link with the bacteria of previous stages. The methanogenic bacteria in turn determine the anaerobic microorganisms' growth rate.

The methanogenic fermentation of concentrated organic waste such as animal dung, sewage sediment and domestic waste can begin in anaerobic conditions without microorganism additive because the needed microflora is always 
available from the waste and environment. But when starting an anaerobic bioreactor, some active ferment is added to the organic waste to intensify the process.

The methanogenic fermentation can run within the range from $0^{\circ} \mathrm{C}$ to $97^{\circ} \mathrm{C}$, but the optimum temperature is $35-40^{\circ} \mathrm{C}$ for methophilic process and $50-55^{\circ} \mathrm{C}$ for thermophilic process [2].

The biogas reactor considered in this work is intended to work with cattle dung. The other types of biomass can also be used in the facility on condition that animal dung or artificial enzymes are added to the biomass. To improve the biological efficiency of the facility it is provided the recirculation of the spent substrate liquid fraction. The microorganism mass is detained at the inner surface of the vessel walls and partitions. To separate the off-balance carbon dioxide the bioreactor tank is divided in hydrolysis and fermentation parts which are situated in different sections of the same vessel.

There is a risk of microorganism imbalance in big bioreactors, because the rate of acid generation can exceed the methane generation rate. This leads to the bioreactor acidulation. That is why it is reasonable to divide bioreactor into preparatory and fermentation parts. In the considered bioreactor the hydrolysis and acid generation processes run in the preparatory tank within the range of $\mathrm{pH}$ from 4.5 to 7 and the range of temperature from 25 to $35^{\circ} \mathrm{C}$.

The structure of the bioreactor tank is shown in fig. 2.

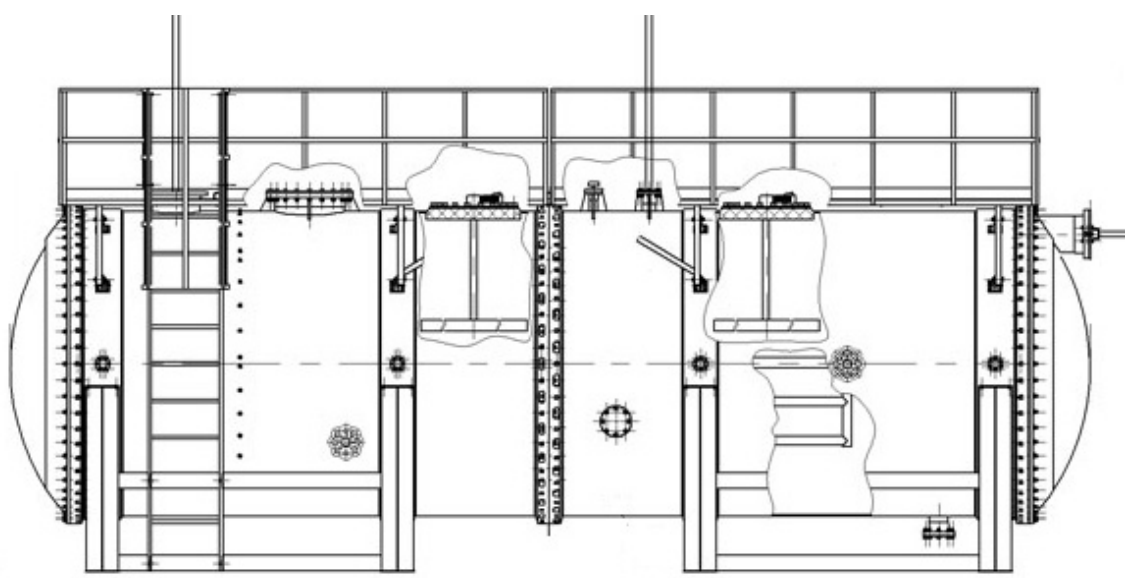

Figure 2: $\quad$ Bioreactor tank.

The operation of biogas facility is possible in the mode of periodic or continuous charging. The preparation of substrate includes grinding to the size of 0.5-5 mm, dilution with pure chlorine-free water to the prespecified dung concentration and heating to the temperature corresponding the chosen methane production mode (mesophilic or thermophilic).

Let's say several words about the role of the mixing system. The uniformity of the liquid is very important for the gasification processes, because it provides 
proper microorganism balance. But the mixture consists of many components with different densities and can be separated into several layers due to the gravitation processes. The temperature of the liquid in the main tank is rather uniform and natural convection is not enough to stop the separation. That is why the main tank of the bioreactor has a mixing device. The preparatory tank's mission is to heat the components and the processes of natural convection are much more intensive there.

\section{The computer model description}

The reaction rate main influential parameters are the heating rate and the uniformity of temperature distribution. A computer model of the bioreactor preparatory tank was designed in terms of current investigation to estimate these parameters. The simulation was made with the help of SolidWorks and SolidWorks Flow Simulation software by Dassault Systems.

Flow Simulation solver is based on the Navier-Stokes equations supplemented by fluid state equations defining the nature of the fluid, and by empirical dependencies of fluid density, viscosity and thermal conductivity on temperature. To predict turbulent flows, the Favre-averaged Navier-Stokes equations are used, where time-averaged effects of the flow turbulence on the flow parameters are considered. Large-scale, time-dependent phenomena are taken into account directly. The same system of equations is used to describe laminar flows. Transitions from laminar to turbulent flow and vice versa are also possible [4].

The governing equations are solved with the finite volume method on a spatially rectangular computational mesh designed in the Cartesian coordinate system with the planes orthogonal to its axes. The mesh is refined locally at the solid/fluid interface before the calculation. It is also refined during the calculation in fluid region in case of significant variation of some calculated physical variable. The time step for the time-dependent problem solution can also be refined. Values of all the physical variables are stored at the mesh cell centers. Due to the FV method, the governing equations are discretized in a conservative form. The spatial derivatives are approximated with implicit difference operators of second-order accuracy. The time derivatives are approximated with an implicit first-order Euler scheme. The viscosity of the numerical scheme is negligible with respect to the fluid viscosity [4].

The general view of the bioreactor model is shown in fig. 3 and the longitudinal section of the model is shown in fig. 4 .

The preparatory tank which is situated at the left side of the model represents a cylindrical vessel $3370 \mathrm{~mm}$ in diameter and $1940 \mathrm{~mm}$ long. The heating system consists of 33 copperplates with dimensions $1000 \times 200 \times 20 \mathrm{~mm}^{3}$.

To study the process of heating and achieving of mesophilic conditions only the preparatory vessel was considered. The maximum temperature was limited at the level of $35-37^{\circ} \mathrm{C}$ since this level of temperature is optimal for the mesophilic bacteria growth. 


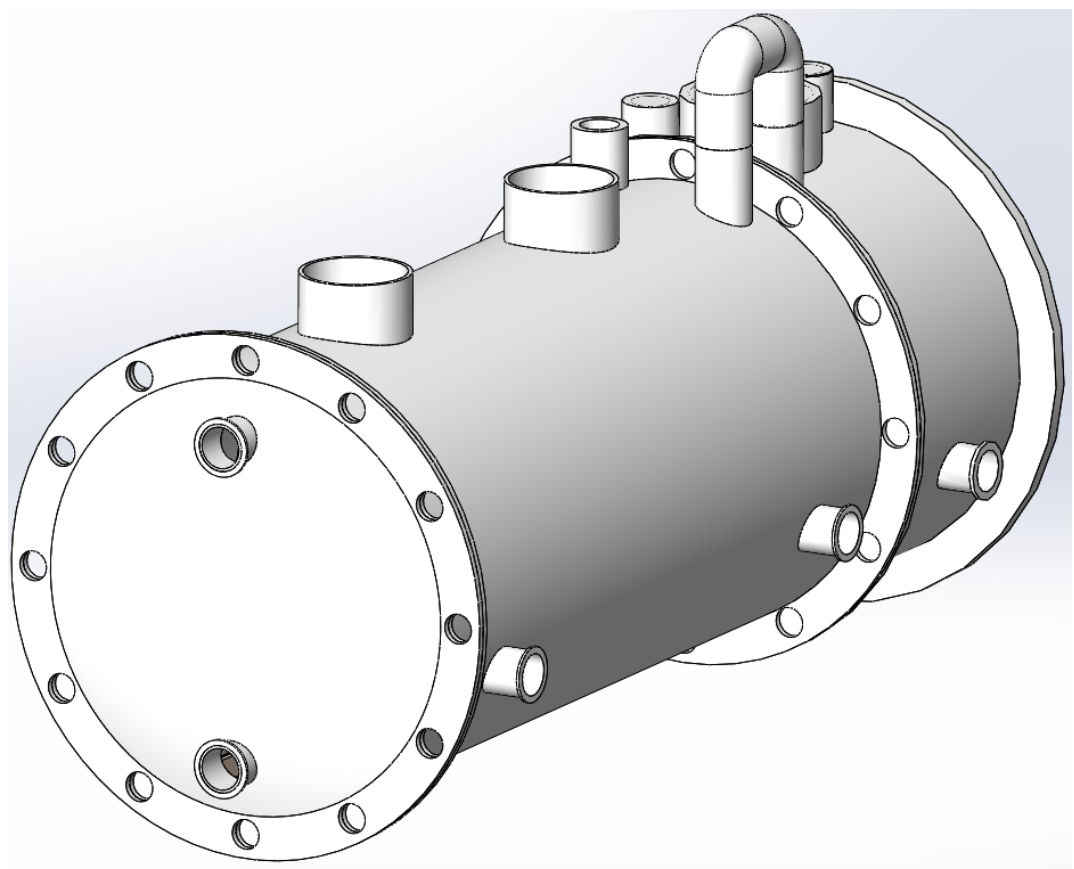

Figure 3: Three-dimensional model of the bioreactor.

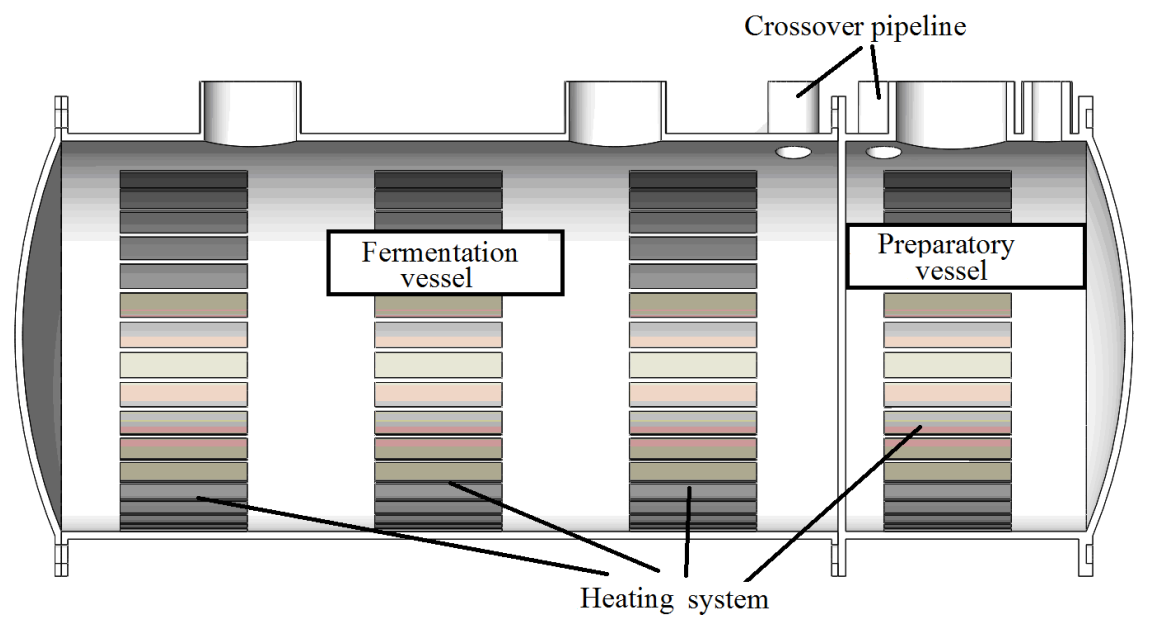

Figure 4: The longitudinal section of the bioreactor model.

The input data of the project corresponding to the hydrolysis stage of mesophilic fermentation process are given in table 1 . The tank was filled with a mixture of water and liquid dung. The initial temperature was set at $20^{\circ} \mathrm{C}$ and the 
calculation termination temperature was $36^{\circ} \mathrm{C}$. The initial pressure was taken atmospheric. The heating elements were considered as volume heat sources with a total power of $(13 \ldots 26) \cdot 10^{3} \mathrm{~W}$.

The heating system power was estimated as a total quantity of heat needed to warm $\sim 20 \mathrm{~m}^{3}$ of liquid from $20^{\circ} \mathrm{C}$ to $36^{\circ} \mathrm{C}$. The acceptable heating time was taken from 15 to 30 hours. The estimation results are given in table 1 .

Table 1: The calculation input data.

\begin{tabular}{|l|c|}
\hline & value \\
\hline Thermophysical properties of liquid dung & \\
\hline density & $1222 \mathrm{~kg} / \mathrm{m}^{3}$ \\
\hline heat capacity & $4060 \mathrm{~J} /(\mathrm{kg} \cdot \mathrm{K})$ \\
\hline heat conductivity & $10 \mathrm{~W} /(\mathrm{m} \cdot \mathrm{K})$ \\
\hline coefficient of dynamic viscosity & $0.005 \mathrm{~Pa} \cdot \mathrm{s}$ \\
\hline Thermophysical properties of water & \\
\hline density & $1000 \mathrm{~kg} / \mathrm{m}^{3}$ \\
\hline heat capacity & $4200 \mathrm{~J} /(\mathrm{kg} \cdot \mathrm{K})$ \\
\hline heat conductivity & $0.6 \mathrm{~W} /(\mathrm{m} \cdot \mathrm{K})$ \\
\hline coefficient of dynamic viscosity & $0.0015 \mathrm{~Pa} \cdot \mathrm{s}$ \\
\hline Initial conditions & \\
\hline temperature & $20^{\circ} \mathrm{C}$ \\
\hline pressure & $1 \mathrm{~atm}$ \\
\hline Water part & $91 \%$ \\
\hline Liquid dung part & $9 \%$ \\
\hline Estimated power of heating system & \\
\hline total heat quantity & $1.4 \cdot 10^{9} \mathrm{~J}$ \\
\hline heating time 15 hours & $26 \cdot 10^{3} \mathrm{~W}$ \\
\hline heating time 30 hours & $13 \cdot 10^{3} \mathrm{~W}$ \\
\hline
\end{tabular}

There were some assumptions taken into account:

1) The fermentation raw stock was considered to be liquid, therefore solid and gaseous inclusions were not taken into account. The thermophysical properties of liquid dung given in table 1 are averaged whereas real properties significantly depend on the dung composition.

2) The possibility of fermentation process and gas extraction on the heating stage was not taken into account, i.e. the composition of the liquid was accepted constant during the heating period.

3) The mixture of water and liquid dung was considered as uniform in the initial time moment.

4) The temperature dependency of thermophysical properties was not considered because the temperature range of the calculation is relatively small.

5) Heat losses to the environment were disregarded. 


\section{Calculation results}

The examples of the calculation results in the form of temperature fields and flow trajectories are given in figs 5 and 6.

The main objective of the investigation was to create a computer model that can be used for the estimation of structural variations of a biogas reactor. The simulation results were compared with the performance of the bioreactor described in section 2 of this work.

The calculation showed that $13 \mathrm{~kW}$ of the heating system total power gives about 30 hours of heating time. Thus, numerical simulation shows the analogous heating time with the estimation formula. This fact can indirectly indicate the model validity. Almost the same time is needed to heat the biogas facility.

The next step was to examine different configurations of heating system. The number of heating elements varied from 10 to 33 for the same power input. If the heating elements are evenly distributed within the tank perimeter, it allows not only to achieve better temperature uniformity, but to avoid the formation of superheated zones with the possibility of bacteria death.

The heating system of 33 elements showed the best results (fig. 5). This configuration of heating system allows us to achieve needed temperature during the relatively small time period. The thermal gradient in the tank volume did not exceed $0.5^{\circ} \mathrm{C}$, so the heating uniformity was also achieved.

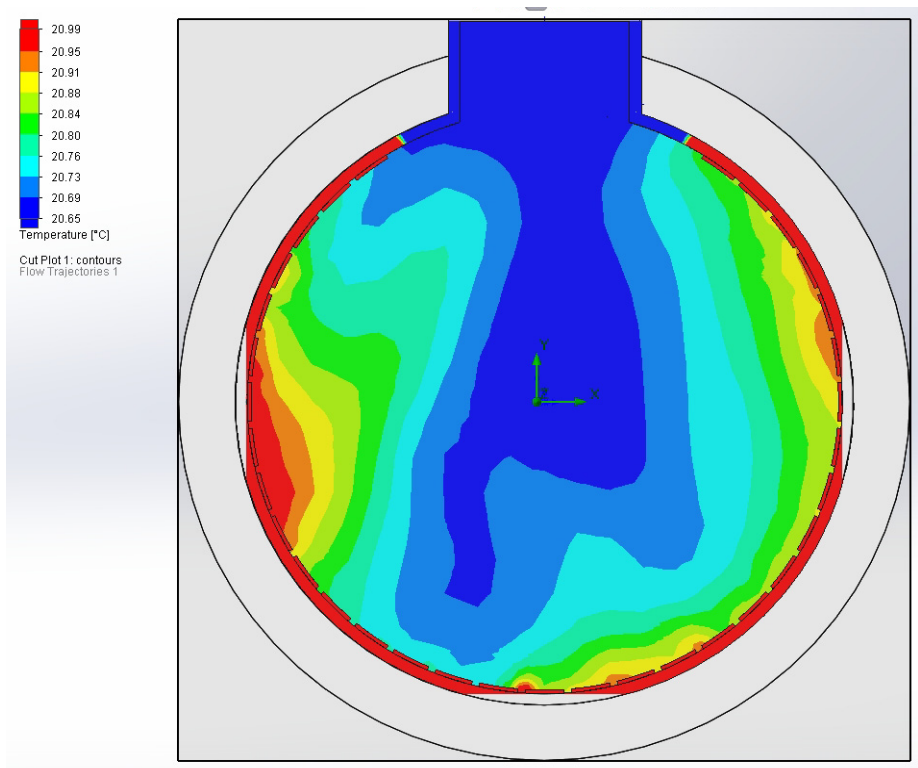

Figure 5: Temperature distribution in the tank central cross section. 


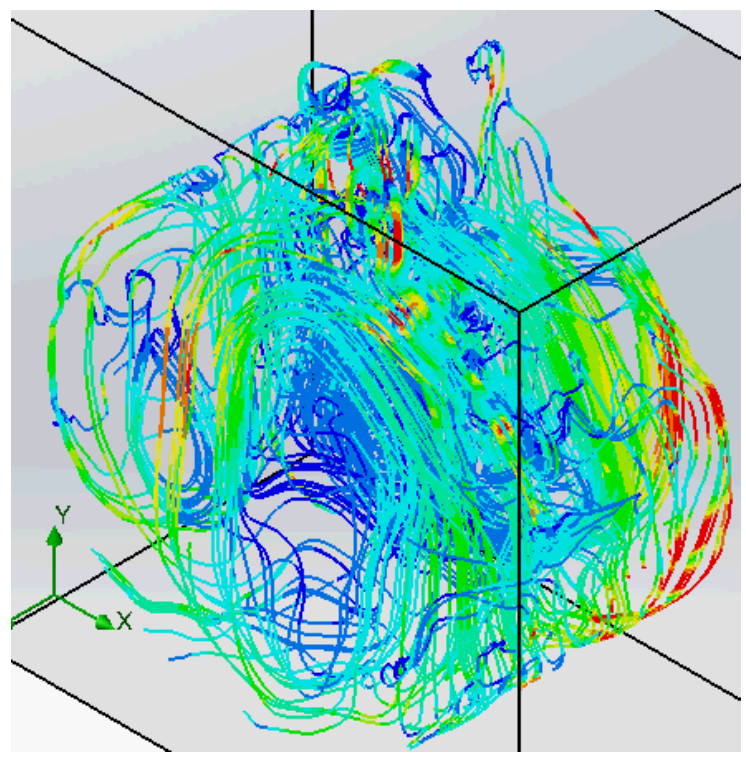

Figure 6: Flow trajectories in the bioreactor tank.

Due to the gravitational processes the mixture in the preparatory tank can be divided into layers with various densities when it is kept in a tank for a long time. The estimation of heat transfer processes in the preparatory tank showed that natural convection leads to the remixing of the liquids and stops the separation.

The results analysis shows the fundamental possibility to use the designed model for thermal and hydraulic estimation of the bioreactor operation modes. It also can be used to approbate the improvements of the facility design.

The next step of the anaerobic bioreactor modeling is the creation of the main tank model which includes the mixing devices of periodic or permanent operation.

\section{References}

[1] Baader, W., Dohne, E. \& Drenndorfer, M., Biogas in Theorie and Practice, Kolos: Moscow, pp. 14-18, 1982.

[2] Arbuzova, E.V. \& Shcheklein, S.E., The problem of energy efficiency of biogas technologies in the climatic conditions of Russia. International scientific journal for alternative energy and ecology, 7, pp. 108-110, 2011.

[3] Arbuzova, E.V., Shcheklein, S.E., Gladivov, I.A., Kholmakov, A.A. \& Shastin, A.G., Technological aspects of efficiency of biomass energy potential in Russia, International scientific journal for alternative energy and ecology, 3, pp. 82-88, 2012.

[4] SolidWorks Flow Simulation 2010 technical reference. 